\title{
THE ANTIRHEUMATIC ACTIVITY OF MUNTINGIA CALABURA L. LEAVES ETHANOL EXTRACT AND ITS FRACTION
}

\author{
JAMILAH SARIMANAH*, KETUT ADNYANA I, ELIN YULINAH SUKANDAR, NENG FISHERI KURNIATI
}

Department of Pharmacology, Clinical Pharmacy, School of Pharmacy, Bandung Institute of Technology, Jawa Barat, Indonesia. Email: jamilahusb@yahoo.co.id

Received: 14 July 2016, Revised and Accepted: 29 September 2016

\section{ABSTRACT}

Objective: Rheumatoid arthritis is chronic inflammation disorder that can be treated with anti-inflammatory drug such as methylprednisolone. Several medicinal plants shave the potential to be used in arthritis therapy, one of which is Muntingia calabura L. The objective of this research was to study the antirheumatic activity of M. calabura leaves ethanol extract and its n-hexane, ethyl acetate, and water fractions in a rheumatoid arthritic rat model.

Methods: Rheumatoid was induced in rats by intraplantar injection of Complete Freund's Adjuvant (CFA) into the right foot paw of Wistar rats. The paw volume was measured by a plethysmometer. The histology of right foot paw was carried out. For chronic CFA inflammation, induced paw edema assay was used, whereas chronic inflammation was assessed by CFA induced arthritis. The histopathology of synovial joints (paw) was carried out.

Result: The results of the study revealed that in CFA-induced arthritic rats, methylprednisolone, $M$. calabura ethanol extract, and its fractions were able to reduce inflammation. Histopathology examination also showed a reduction of in cartilage destruction, influx of inflammatory cells, pannus formation, fibrin deposition, and synovitis.

Conclusion: M. calabura L. n-hexane fraction showed a better anti-rheumatic activity in rats among other fractions.

Keywords: Muntingia calabura L. leaves, Ethanol extract, N-hexane fraction, Ethyl acetate fraction, Antirheumatic.

(C) 2017 The Authors. Published by Innovare Academic Sciences Pvt Ltd. This is an open access article under the CC BY license (http://creativecommons. org/licenses/by/4. 0/) DOI: http://dx.doi.org/10.22159/ajpcr.2017.v10i1.14102

\section{INTRODUCTION}

Formerly medicinal herb is only used for alternative medication, but currently many studies prove the active substance content of plant with medicinal benefit so that it can be used as a drug in curing or preventing certain disease or although it contains no certain active substance but resultant effect or synergy of various substances functioning as curing medicine.

The aim of this study was to determine the potential of leave extract Muntingia calabura L, n-hexane fraction, ethyl acetate fraction, and water fraction to decreased levels of interleukin 1 beta (IL-1 $\beta$ ) and repaired joint tissue of arthritis rats induced by Complete Freund's Adjuvant (CFA).

Rheumatoid arthritis is a chronic, progressive, and systemic inflammation disorder with unknown etiology and is a polyarticular disease that frequently affects joints in a symmetrical manner.

Several medicinal plants are empirically known to have a therapeutic effect when used as alternative medication for various illnesses. One such example is the calabur tree (M. calabura L.) a plant belonging to the Muntingia genus and the Tiliaceae family. Although the plant is mainly distributed in tropical America, it can also be found in gardens and roadsides in Indonesia. This plant is rich in flavonoids, with flavones, flavanones, flavans, and biflavans as the major compounds and also contains polyphenols and steroids, which are anti-inflammatory compounds that can be used for the treatment of rheumatoid arthritis. In fact, many studies regarding the pharmacological activities of $M$. calabura support its traditional use for the treatments of pain, fever, and inflammatory illness [4,9], and antibacterial [7], antidiabetic [2], antimicrobial [3,11], antioxidant [1,5,10], antiproliferative [10], and antinociceptive agents $[4,8,9]$.
In this study, we obtained an ethanol extract of $M$. calabura leaves, which was then separated into several fractions. The aim of this study was to determine the potential anti rheumatic activities of the ethanol extract, and the n-hexane fraction, ethyl acetate, and water fractions and their ability to decrease levels of IL-1 $\beta$ and repair the joint tissue of CFA-induced arthritis in rats.

\section{MATERIALS AND METHODS}

\section{Plant material}

The leaves of $M$. calabura L. were collected from Surakarta, Central Java, Indonesia, in March 2013, and were identified and authenticated at herbarium bandungense, SITH, Bandung Institute of Technology, Bandung, Indonesia.

\section{Chemicals and reagents}

CFA (Sigma Aldrich, USA), methylprednisolone (Tianjin Tianyao Pharmaceuticals Co., LTD., China), boulin, ethanol, paraffin liq., xylene, Elisa Kit IL-1 $\beta$ (Elabscience) were used. Other chemicals and reagents used in this study were of analytical grade and provided by approved organizations.

\section{Experimental animals}

Male Wistar rats with body weights $150-200$ g were provided by the Pharmacology Laboratory, Faculty of Pharmacy, Setia Budi University, Surakarta, Indonesia. Animals were placed in polypropylene cages in a controlled room at $24^{\circ} \mathrm{C} \pm 1^{\circ} \mathrm{C}$ and a relative humidity of $60-70 \%$ with standard environmental conditions (12 h light and $12 \mathrm{~h}$ dark cycle). The animals were maintained with a standard pellet diet and water ad libitum. All the experimental protocols used in this study were approved by UNDIP the Institutional Animal Ethical Committee, 232/ FC/FKM/2014. 


\section{Methods}

\section{Extract and fraction preparation}

About $50 \mathrm{~g}$ of grounded M. calabura leaves were placed in a soxhlet apparatus, and $95 \%$ ethanol was added. The extraction processes were carried out until a clear filtrate was then obtained. The extract was then concentrated using a vacuum rotary evaporator. Dried extract was used for the further studies.

About $50 \mathrm{~g}$ of the ethanol extract was diluted using $100 \mathrm{ml}$ ethanol and $400 \mathrm{ml}$ water and was and then fractionated into n-hexane, ethyl acetate and water, respectively, fractions using liquid-liquid extraction. Each fraction was concentrated a using vacuum rotary evaporator.

\section{CFA-induced arthritis in rats}

Rheumatoid arthritis was induced in the rats by the intraplantar injection of $0.1 \mathrm{ml}$ of CFA in the right hind paw. The animals were then divided into six groups, the arthritic control (Group 1), and arthritic animals treated with standard methylprednisolone (Group 2), arthritic animals treated with test extract leaves extract (Group 3), n-hexane fraction (Group 4) the ethyl acetate fraction (Group 5), arthritic animals treated with test extract water fraction (Group 6). The extract of fraction was given daily at 5 after CFA injection. IL-1 $\beta$ levels were measured at days $0,5,10,15$, and 20 . The animals were sacrificed at day 21 to study the IL-1 $\beta$ cytokines production and the histological analysis of the synovial fluid.

\section{Histological analysis}

The right hind paws of the sacrificed animals were isolated and fixed in $10 \%$ formalin buffered. The paws were decalcified in 5\% formic acid, processed for paraffin embedding, sectioned at thickness of $5 \mu \mathrm{m}$, and subsequently stained with haematoxylin-eosin for examination under a light microscope with $\times 100$ magnifications. Sections were observed for the presence of the cartilage, the joint cavity and pannus formation.

\section{The cytokine production measurement}

To investigate the antirheumatoid of $M$. calabura extract, and fractions, the foot sole membrane of the rats were centrifuged and the supernatant collected and stored at $-20^{\circ} \mathrm{C}$ to be assayed for cytokine levels. The concentration of IL-1 $\beta$ in the supernatant of the foot sole membranes was determined using an Elisa Kit, according to the manufacturer's instructions (Elabscience).

\section{RESULTS AND DISCUSSION}

Effect of $M$. calabura ethanol extract and its fractions on CFA induced rat paw edema

Subplantar administration of CFA in rat's paws results in significant inflammation which was steadily maintained for 20 days (Table 1). 1 day after the CFA injection, an immune response occurred observed by a marked increase in the edema volume, resulting in secondary arthritis. The results showed that methylprednisolone significantly decreased the edema volume at day 10, 15 and 20 compared to the control group, which was expected as methylprednisolone is a known and an approved anti-inflammatory drug. Similarly, the M. calabura ethanol extract and fractions significantly also decreased the edema volume compared to the control group starting at day 10 (Table 2).

The anti-inflammatory effects of the extracts and fractions on the chronic inflammation process were evaluated using a rat paw edema model. The results show that CFA-induced edema at day 10 was significantly inhibited by the ethanol extracts and fractions of M. calabura. Reductions in edema volume of more than $20 \%$ were observed for the water fraction, ethyl acetate fraction, n-hexane fraction, and ethanol extract, in increasing order. These values were similar to that of methylprednisolone, which reduced the edema volume by $25 \%$ at day 10.
The edema volume reduction data are further supported by measurements of IL-1ß concentrations (Table 3). A significant decrease of IL-1 $\beta$ levels was observed for all groups with the n-hexane fraction showing the highest reduction. Together, these data support the hypothesis that $M$. calabura has an effect on the mediators of the inflammation processes.

\section{Histological analysis}

To further determine the effects of $M$. calabura on the inflammation process, a histological analysis was performed on the right hind paws of the test animals (Fig. 1). In the control group, the tissues of arthritic rats showed cartilage destruction, an influx of inflammatory cells, pannus formation, fibrin deposition, synovitis, and chronic inflammation (Fig. 1a). In the methylprednisolone-treated group, however, it could be observed that cartilage destruction was avoided, and vascular proliferation and synovial cavities can still be clearly seen (Fig. 1b). This observation is to be expected and is in line with the result of the previous assays in which the methylprednisolone group decreased the edema volume and levels of IL-1 $\beta$ significantly. As for n-hexane and ethyl acetate fraction-treated rats, minimal inflammation occurred and an influx of few inflammatory cells in the synovium was observed, evidenced by the disturbed synovial lining and minimal lymphocyte influx (Fig. 1d and e). These observations also support the results of the previous assays in which the n-hexane and water fraction showed a decrease in IL-1 $\beta$ levels (Table 3 ). IL- $1 \beta$ is a potent mediator which, when absent or at low levels, prevents cartilage damage, synovitis, and inflammation. Both the water fraction and ethanol extract-treated rats showed moderate cartilage destruction, synovial space thickening, and influx of few inflammatory cells and lymphocytes (Fig. 1c and 1f). These observations can be attributed to the fact that the ethanol extract and water fraction showed the lowest and third-lowest decrease in IL-1 $\beta$ levels, respectively, and thus moderate inflammation still occurred.

Overall, the results of this study showed that n-hexane, ethyl acetate, and water fractions, as well as the ethanol extract of $M$. calabura have inflammatory activities almost equal to that of methylprednisolone because the results show that CFA-induced edema at day 10 was significantly inhibited by the ethanol extracts and fractions of M. calabura. Reductions in edema volume of more than $20 \%$ were observed for the water fraction, ethyl acetate fraction, n-hexane fraction, and ethanol extract, in increasing order. These values were similar to that of methylprednisolone, which reduced the edema volume by $25 \%$ at day 10. The more cartilage its mean reductions in edema volume of few than methylprednisolone, n-hexane fraction, and ethanol extract.

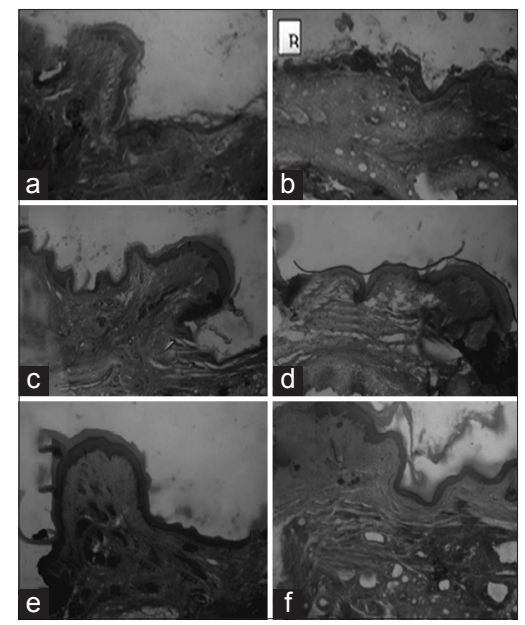

Fig. 1: Histological analysis of the rats right hind paws. Staining $\mathrm{H}$ and $\mathrm{E}$, magnification $\times \mathbf{1 0 0}$. (a) Control group treated with critical micelle concentration-sodium, test group treated with

(b) methylprednisolone, (c) ethanol extract, (d) n-hexane fraction, (e) ethyl acetate fraction, (f) and water fraction 
Table 1: Effect of Muntingia calabura L. leaves etanol extract and its fraction on CFA induced rat paw edema volume

\begin{tabular}{|c|c|c|c|c|c|c|c|}
\hline \multirow[t]{2}{*}{ S. No. } & \multirow[t]{2}{*}{ Group } & \multicolumn{6}{|c|}{ Edema volume (ml) after CFA administration at day } \\
\hline & & $\mathbf{0}$ & 1 & 5 & 10 & 15 & 20 \\
\hline 1 & CMC Na $0.5 \%$ & $0.01 \pm 0.004$ & $0.04 \pm 0.007$ & $0.05 \pm 0.011$ & $0.05 \pm 0.01$ & $0.05 \pm 0.01$ & $0.03 \pm 0.006$ \\
\hline 3 & Leaves extract $100 \mathrm{mg} / \mathrm{kg}$ bw & $0.01 \pm 0.006$ & $0.04 \pm 0.006$ & $0.032 \pm 0.009$ & $0.03 \pm 0.007$ & $0.03 \pm 0.005$ & $0.03 \pm 0.006$ \\
\hline 4 & $\mathrm{n}$-hexane fraction $100 \mathrm{mg} / \mathrm{kg}$ bw & $0.01 \pm 0.005$ & $0.04 \pm 0.001$ & $0.04 \pm 0.009$ & $0.04 \pm 0.006$ & $0.03 \pm 0.005$ & $0.03 \pm 0.006$ \\
\hline 5 & Ethyl acetate fraction $100 \mathrm{mg} / \mathrm{kg} \mathrm{bw}$ & $0.01 \pm 0.006$ & $0.04 \pm 0.001$ & $0.04 \pm 0.005$ & $0.04 \pm 0.009$ & $0.03 \pm 0.007$ & $0.03 \pm 0.005$ \\
\hline 6 & Water fraction $100 \mathrm{mg} / \mathrm{kg} \mathrm{bw}$ & $0.01 \pm 0.005$ & $0.04 \pm 0.001$ & $0.04 \pm 0.005$ & $0.04 \pm 0.006$ & $0.03 \pm 0.008$ & $0.03 \pm 0.007$ \\
\hline
\end{tabular}

The data above shows the mean \pm SD. $n=5$ of each group. CMC: Critical micelle concentration, CFA: Complete Freund's Adjuvant

Table 2: Percentage (\%) of inflammatory inhibition after CFA administration

\begin{tabular}{|c|c|c|c|c|c|c|}
\hline \multirow[t]{2}{*}{ S. No. } & \multirow[t]{2}{*}{ Group } & \multicolumn{5}{|c|}{ Percentage (\%) of inflammatory inhibition after CFA administration at day } \\
\hline & & 1 & 5 & 10 & 15 & 20 \\
\hline 1 & Methylprednisolone $0.68 \mathrm{mg} / \mathrm{kg}$ bw & $21.3 \pm 30.69$ & $33.6 \pm 11.92$ & $25^{*} \pm 17.67$ & $50.3^{*} \pm 15.83$ & $52 * \pm 8.37$ \\
\hline 2 & Leaves extract $100 \mathrm{mg} / \mathrm{kg}$ bw & $25 \pm 4.8$ & $26 \pm 24.08$ & $23.3^{*} \pm 116.6$ & $41 * \pm 17.69$ & $43 * \pm 13.04$ \\
\hline 3 & $\mathrm{n}$-hexane fraction $100 \mathrm{mg} / \mathrm{kg} \mathrm{bw}$ & $29 \pm 41.29$ & $35 \pm 25.99$ & $21.66^{*} \pm 21 . W$ & $33 * \pm 21.09$ & $43 \pm 13.04$ \\
\hline 4 & Ethyl acetate fraction $100 \mathrm{mg} / \mathrm{kg}$ bw & $14 \pm 12.94$ & $28.67 \pm 19.38$ & $20^{*} \pm 29.81$ & $36.33^{*} \pm 25.34$ & $38^{*} \pm 14.40$ \\
\hline 5 & Water fraction & $19 \pm 20.74$ & $28.67 \pm 19.38$ & $20 * \pm 12.64$ & $40 * \pm 14.75$ & $35 * \pm 12.25$ \\
\hline
\end{tabular}

The data above shows the mean \pm SD. $n=5$ of each group. *Significantly different from control group ( $<<0.05)$. CFA: Complete Freund's adjuvant

Table 3: Effect of Muntingia calabura L.'s leaves ethanol extract and fraction on level of IL-1 $\beta$ in foot sole homogenate

\begin{tabular}{lll}
\hline S. No. & Group & $\begin{array}{l}\text { Concentration } \\
\text { of IL-1 } \boldsymbol{\beta}(\mathbf{p g} / \mathbf{m l})\end{array}$ \\
\hline 1 & CMC $0.5 \%$ & $5000 \pm 0$ \\
2 & Methylprednisolone $0.68 \mathrm{mg} / \mathrm{kg} \mathrm{bw}$ & $2261 \pm 1720^{*}$ \\
3 & Leaves extract $100 \mathrm{mg} / \mathrm{kg} \mathrm{bw}$ & $3951 \pm 37^{*}$ \\
4 & n-hexane fraction $100 \mathrm{mg} / \mathrm{kg} \mathrm{bw}$ & $2536 \pm 1607^{*}$ \\
5 & Ethyl acetate fraction $100 \mathrm{mg} / \mathrm{kg} \mathrm{bw}$ & $3251 \pm 3350^{*}$ \\
6 & Water fraction $100 \mathrm{mg} / \mathrm{kg} \mathrm{bw}$ & $2961 \pm 63^{*}$ \\
\hline
\end{tabular}

Values are expressed as mean $\pm \mathrm{SD},{ }^{*} \mathrm{p}<0.001$ significant as compared with control group. IL-1ß: Interleukin 1 beta, CMC: Critical micelle concentration

Histopathological examinations, showed that synovial thickening one of the signs of inflammation, were highly reduced by ethanol extract, ethyl acetate, n-hexane, and water fractions, in descending order. In histopathologic examination, the line thickening on synovial membrane appeared most obviously in the first (control) group of critical micelle concentration (CMC), followed by the sixth group of water fraction, the fourth (n-hexane), the fifth (ethyl acetate fraction), the third (leaves ethanol extract), and the second groups of methylprednisolone (control). The result of this research showed that n-hexane, ethyl acetate, and water fractions, and M. calabura L. leaves had inflammatory inhibition almost equal to methylprednisolone as the control. M. calabura L. leaves ethanol extract and n-hexane fraction showed the best result among other fraction in reducing the inflammation in CFA induced arthritis rat. In histopathological examination, the line thickening on synovial membrane appeared most obviously in the first (control) group of CMC, followed by the sixth group of water fraction, the fourth (n-hexane), the fifth (ethyl acetate fraction), the third (leaves ethanol extract), and the second groups of methylprednisolone (control). Histopathology examination also showed a reduction of in cartilage destruction, influx of inflammatory cells, pannus formation, fibrin deposition, and synovitis.

The result of the study revealed a significant decrease of IL-1 $\beta$ level at all group treated. $\mathrm{N}$-hexane fraction showed the best result among other fractions [8], this result of the present study demonstrate the antiarthritis potential of Helianthus Annus leaves in the arthritic activity.

\section{CONCLUSION}

The ethanol extract of $M$. calabura L. and its fractions are able to alleviate arthritic rats. The n-hexane fraction showed the most potent anti-rheumatic activity compared to ethyl acetate and water fractions.

\section{REFERENCES}

1. Balakrishnan KP, Narayanaswamy N, Duraisamy A. Tyrosinase inhibition and anti-oxidant properties of Muntingia calabura extracts: In vitro studies, ITC $\mathrm{R}$ and $\mathrm{D}$ centre, Peenya industrial area phase I, Bangalore 560 058, India. Int J Pharm Bio Sci 2011;2(1):294-303.

2. Khan YM, Ramadan D, Mundasada SC, Kumar NS, Kashyap HR, Chikkanna D. In vitro antidiabetic activity of Muntingia calabura root proteins. Int J Pharm Pharm Sci 2015;4(10):1526-34.

3. Banu K, Kalaivani K. GSMS/Ms analysis of Muntingia calabura steam and its antimicrobial effect, Periyar University, Salem. Int J Pharm Pharm Sci 2015;4(8):

4. Lin FL, Chen JJ, Shih CD. Antinociceptive and anti-inflammatory activity of the water-soluble extracts from leaves of Muntingia calabura, department pharmacy, graduate. J Clin Exp Pharmacol 2006;2(4):439-42.

5. Siddiqua A, Premakumari KB, Sultana R, Vithya, Savitha. Antioxidant activityand estimation of total phenolic content of Muntingia calabura by colorimetry, Dayananda Sagar college of pharmacy, Kumaraswamy, lay out, Bangalore, India. Int J Chem Tech Res 2010;2(1):205-8.

6. Suralkar AA. Anti arthritis potensial of helianthus annuus in laboratory animals. Asian J Pharm Clin Res 2015;8(6):

7. Zakaria ZA, Fatimah CA, Iais AM, Zaiton H, Henie EF, Sulaiman MR, et al. The in vitro antibacterial activity of Muntingia calabura extracts. Int J Pharmacol 2006;2(4):439-42.

8. Zakaria ZA, Somchit MN, Sulaiman MR, Jais AM, Fatimah CA Effects of various receptor antagonists, $\mathrm{pH}$ and enzymes on Muntingia calabura antinociception in mice. Res J Pharmacol 2008;2(3):31-7.

9. Zakaria ZA, Nor RN, Jais AM, Somcit MN, Ghani ZD, Kader AA, et al. Antinociceptive, anti-inflammatory and antipyretic effects of Muntingia calabura aqueous extract in animal models. J Nat Med 2008;62(2):179-87.

10. Zakaria ZA, Mohamed AM, Jamil NS, Rofiee MS, Hussain MK, Sulaiman MR, et al. In vitro antiproliferative and antioxidant activities of the extracts of Muntingia calabura leaves. Am J Chin Med 2011;39(1):183-200.

11. Zakaria ZA, Sulfian AS, Ramasang K, Ahmat N, Sulaiman NR, Arifah KA, et al. In vitro antimicrobial of Muntingia calabura extrac and fraction. Afr J Microbiol Res 2010;4(4):304-8 